\title{
Analysis of Myocardial Infarction Time Course in Women Compared With Men in Upper Silesia Population in 30 Day Follow-Up
}

\author{
Damian KAwECKI, ${ }^{1} \mathrm{MD}$, Andrzej Robert TomasiK, ${ }^{1} \mathrm{MD}$, \\ Beata Morawiec, ${ }^{1}$ MD, Wojciech JaCHEĆ, ${ }^{1}$ MD, \\ Celina WoJciechowsKa, ${ }^{1} \mathrm{MD}$, Renata RYBCZYK, ${ }^{1} \mathrm{MD}$, \\ Wojciech MiLeJSKI, ${ }^{1}$ MD, Izabela Świtalska-JANICZEK, ${ }^{1}$ MD, \\ Brygida Przywara-Chowaniec, ${ }^{1} \mathrm{MD}$, and Ewa Nowalany-KozIElsKa, ${ }^{1} \mathrm{MD}$
}

\section{SUMmary}

The aim of the study was to compare the course of myocardial infarction in women versus men in Upper Silesia, an industrial region in the south of Poland.

The study comprised 1003 patients with either ST-elevation myocardial infarction (STEMI) or non-ST-elevation myocardial infarction (NSTEMI). The patients were divided into group 1 (300 females) and group 2 (control, 703 males). The groups differed significantly with respect to age, incidence of hypertension, diabetes, and smoking. In group 1 STEMI occurred significantly less frequently than NSTEMI. Taking this into account, we divided the studied cohort into group A (STEMI patients) and group B (NSTEMI patients), each subdivided into women and men.

In the 30 day long follow-up, group 1 patients had significantly lower creatine kinase activity, higher occurrence of ventricular tachycardia, lower percentage of intra-aortic balloon pump use, and longer hospital stay compared with group 2. Group 1 was characterized by significantly higher mortality and target lesion reocclusion (TLR).

The medical course of myocardial infarction in women is similar to that in men, as is the treatment of acute coronary syndrome. In our study, patients from both groups underwent invasive examination with consecutive interventional treatment with similar frequency. However, this finding is not reflected in the outcomes. Women had higher risks of death and TLR in 30 day follow-up. Taking this into consideration, we should attempt to identify the factors responsible for this situation by expanding the analysis to a larger population to allow firm conclusions to be drawn. (Int Heart J 2009; 50: 711-721)

Key words: PCI, Women, Myocardial infarction

CARDiOVASCULAR diseases are the main cause of death among women. Previous studies have demonstrated the influence of gender on the results of

From the ${ }^{1} 2^{\text {nd }}$ Department of Cardiology, Zabrze, Medical University of Silesia, Katowice, Poland. Address for correspondence: Damian Kawecki, MD, 41-800 Zabrze, Skłodowskiej-Curie 10, Poland. Received for publication March 3, 2009. Revised and accepted June 22, 2009. 
treatment and mortality of acute coronary syndromes. ${ }^{1-3)}$

The majority of these papers indicate that women suffer from myocardial infarction in older age more often compared with men, which is worth stressing, especially knowing that morbidity and mortality increase with age and age-related risk factors. ${ }^{4)}$ Vaccarino ${ }^{5)}$ and Hochman ${ }^{6}$ have shown that age is independently associated with the differences in the natural course of coronary artery disease between women and men. Women are more prone to have arterial hypertension, diabetes, dyslipidemia, peripheral artery disease, and heart failure. ${ }^{1,7)}$ Some authors stress the delay in diagnosis and the institution of appropriate treatment in women. ${ }^{8)}$ Despite all these proved facts, the impact of gender itself on mortality in acute coronary syndromes is uncertain. Is the female gender an independent risk factor of acute coronary syndromes? The relation between gender and death after adjustment for percutaneous coronary intervention is also unknown. However, revascularization is less frequently performed in women. ${ }^{9,10)}$

Our study is an analysis of gender influence on the management of acute coronary syndrome and the outcome of this treatment defined by the occurrence of major adverse cardiac events (reocclusion, death, stroke) in 30 day followup in Upper Silesia (an industrial region). The statistics prove how serious a problem acute coronary syndromes are in this part of Poland. Cardiovascular diseases are the major cause of death among the inhabitants of Upper Silesia. Expanding the analysis to an international level, the rate of premature death in this region is more than two-fold higher than that of other European Union countries. $^{11)}$

\section{Methods}

Patients admitted to the $2^{\text {nd }}$ Department of Cardiology in Zabrze between 1999 and 2006 were enrolled in the study. Initial evaluation comprised physical examination, electrocardiography, and relevant laboratory investigations. Depending on the diagnosis, the patients were transferred from the emergency room either to the catheter lab or Intensive Cardiology Care Unit. Myocardial infarction diagnostic criteria were chest pain lasting more than 20 minutes, specific electrocardiographic changes, or positive findings for myocardial necrosis markers. Patients fulfilling European Society of Cardiology criteria were scheduled for coronary angiography. Angiography was performed using the Seldinger technique and femoral artery puncture. At the same time primary coronary percutaneous angioplasty was performed, some selected patients were referred to coronary artery bypass graft surgery, and very rarely patients were scheduled for further medical treatment. Patients were administered anticoagulants, antiplatelet drugs, beta-blockers, nitrates, angiotensin converting enzyme inhibitors, and 
statins. Monitoring consisted of electrocardiography, the level of myocardial necrosis factors, and echocardiographic examination (LG, Vivid 4). Patients were evaluated for occurrence of major adverse cardiac events after 30 day follow-up.

Primary endpoints included target lesion reocclusion (eg, consecutive myocardial infarction or unstable angina) or death. The secondary endpoint was stroke.

Statistical analysis: The data were first checked for normality of distribution (Shapiro-Wilks test), and then tested with Wilcoxon's matched pair test, the Mann-Whitney U test, and multivariate logistic regression techniques (Rosenbrock and quasi-Newton methods). For the analysis of quantitative data, the $\chi^{2}$ test with Yates correction was used.

\section{Results}

A total of 1003 consecutive patients were enrolled in the study. They were divided into group 1 consisting of 300 women and group 2 consisting of 703 men. Demographic data are presented in Table I. Women were older in comparison to men, had higher rates of arterial hypertension and diabetes, and were less frequently cigarette smokers. Clinical characteristics of the patients at presentation are shown in Table II. Non-ST-elevation myocardial infarction (NSTEMI) occurred more frequently among women, while ST-elevation myocardial infarction (STEMI) was more common among men. Admission heart rate was significantly higher in women. Coronary angiography was performed in 281 women and 666 men. Angiographic data are presented in Table III. Men had a greater incidence of single vessel disease. The groups had similar duration of infarction pain, time to admission, time spent in the emergency room, as well as similar medical treatments (coronary artery bypass grafting and percutaneous coronary

Table I. Demographic Data

\begin{tabular}{lccc}
\hline Characteristic & $\begin{array}{c}\text { Women } \\
(n=300)\end{array}$ & $\begin{array}{c}\text { Men } \\
(n=703)\end{array}$ & $P$ \\
\hline Age (years) & $65.1 \pm 10.8$ & $59.0 \pm 11.2$ & $<0.001$ \\
Hypertension, $n(\%)$ & $199(66.3)$ & $367(52.2)$ & $<0.001$ \\
Diabetes, $n(\%)$ & $92(30.8)$ & $118(16.8)$ & $<0.001$ \\
Dyslipidaemia, $n(\%)$ & $111(37.0)$ & $235(33.4)$ & NS \\
Family history, $n(\%)$ & $106(35.3)$ & $229(32.6)$ & NS \\
Smoking, $n(\%)$ & $123(41.0)$ & $457(65.0)$ & $<0.001$ \\
History of AMI, $n(\%)$ & $48(16.0)$ & $122(17.4)$ & NS \\
History of PCI, $n(\%)$ & $26(8.7)$ & $70(10.0)$ & NS \\
History of CABG, $n(\%)$ & $7(2.3)$ & $19(2.7)$ & NS \\
\hline
\end{tabular}


Table II. Clinical Characteristics

\begin{tabular}{lccc}
\hline Clinical characteristic & $\begin{array}{c}\text { Women } \\
(n=300)\end{array}$ & $\begin{array}{c}\text { Men } \\
(n=703)\end{array}$ & $P$ \\
\hline Killip-Kimball classification, $n(\%):$ & & & \\
$\quad$ I & $207(69)$ & $505(72)$ & NS \\
II & $55(18)$ & $119(17)$ & NS \\
III & $8(3)$ & $22(3)$ & NS \\
IV & $30(10)$ & $57(8)$ & NS \\
RR (mmHg): & & & \\
$\quad$ Systolic & $130.1 \pm 27.2$ & $129.7 \pm 25.1$ & NS \\
$\quad$ Diastolic & $80.9 \pm 15.4$ & $80.6 \pm 16.89$ & NS \\
Heart rate & $80.66 \pm 18.68$ & $78.37 \pm 16.89$ & 0.0345 \\
Ejection fraction $(\%)$ & $44.1 \pm 10.5$ & $43.2 \pm 10.8$ & NS \\
STEMI, $n(\%)$ & $205(68.3)$ & $541(77.0)$ & 0.0021 \\
NSTEMI, $n(\%)$ & $95(31.7)$ & $162(23.0)$ & 0.0021 \\
Right ventricle infarction, $n(\%)$ & $10(3.3)$ & $20(2.8)$ & NS \\
AMI location: & & & \\
$\quad$ Anterior, $n(\%)$ & $126(42.0)$ & $271(38.6)$ & NS \\
$\quad$ Inferolateral, $n(\%)$ & $174(58.0)$ & $432(61.4)$ & NS \\
\hline
\end{tabular}

intervention).

Further analysis showed that an intra-aortic balloon pump was used in one woman and 13 men, and that women had lower maximal creatine kinase activity relative to men $(1333.7 \pm 1461.4$ versus $1895.1 \pm 2204.4[\mathrm{IU} / \mathrm{L}] ; P<0.001)$. Women suffered more frequently from ventricular tachycardia $(P=0.0364)$ and experienced a longer hospitalization time than men $(9.19 \pm 5.34$ versus $8.25 \pm$ 7.07 days; $P=0.0306)$.

Haemorrhagic complications occurred with similar frequencies in both groups. Medical treatment administered after hospital discharge differed between the groups: women more frequently were prescribed calcium channel inhibitors, while men were more frequently given angiotensin converting enzyme inhibitors.

Death and TLR were observed more frequently in women compared to men, but the groups did not differ in the incidence of stroke (Figure 1).

The higher frequency of NSTEMI occurrence among female patients has already been proved. ${ }^{6}$ In order to explain such a fact and show any differences in the effect of gender between STEMI and NSTEMI, we divided the general population once again first into STEMI (group A) and NSTEMI patients (group B) with further subdivision into females and males. We compared the major demographic, clinical, and angiographic data as well as endpoints between women and men in each group. Analysis of the NSTEMI group showed that women were older than men $(P=0.0001)$ and more frequently suffered from hypertension $(P=0.0159)$. We also observed a lower percentage of smokers $(P<0.001)$ 
Table III. Angiographic Data

\begin{tabular}{|c|c|c|c|}
\hline Data & Women $(n=281)$ & $\operatorname{Men}(n=666)$ & $P$ \\
\hline \multicolumn{4}{|l|}{ Duration of infarct pain (hours): } \\
\hline STEMI & $7.76 \pm 13.07$ & $7.60 \pm 12.60$ & NS \\
\hline NSTEMI & $13.21 \pm 14.11$ & $11.11 \pm 13.12$ & NS \\
\hline Time of transportation (minutes): & $29.79 \pm 21.16$ & $30.39 \pm 20.50$ & NS \\
\hline \multicolumn{4}{|l|}{ Door-to-needle time (minutes): } \\
\hline STEMI & $42.91 \pm 49.09$ & $36.99 \pm 36.08$ & NS \\
\hline NSTEMI & $114.3 \pm 179.2$ & $120.8 \pm 150.8$ & NS \\
\hline \multicolumn{4}{|l|}{$\begin{array}{l}\text { Needle-to-reperfusion time } \\
\text { (minutes): }\end{array}$} \\
\hline STEMI & $36.49 \pm 24.46$ & $35.55 \pm 23.97$ & NS \\
\hline NSTEMI & $67.45 \pm 89.30$ & $54.13 \pm 34.13$ & NS \\
\hline \multicolumn{4}{|l|}{ Coronary artery disease, $n(\%)$ : } \\
\hline - one-vessel disease & $97(34.5)$ & $273(40.0)$ & 0.0402 \\
\hline - two-vessel disease & $74(26.0)$ & $201(29.5)$ & NS \\
\hline - three-vessel disease & $107(37.5)$ & $201(29.5)$ & NS \\
\hline - normal angiography & $6(2.0)$ & $4(0.6)$ & NS \\
\hline \multicolumn{4}{|l|}{ IRA $n(\%)$ : } \\
\hline - LM & $6(2.1)$ & 11(1.7) & NS \\
\hline - LAD & $108(38.4)$ & $243(36.5)$ & NS \\
\hline$-\mathrm{Cx}$ & 55 (19.6) & $155(23.3)$ & NS \\
\hline - RCA & $106(37.6)$ & $250(37.5)$ & NS \\
\hline - IRA not defined & $6(2.3)$ & $7(1.0)$ & NS \\
\hline Primary PCI, $n(\%)$ & $238(79.3)$ & $568(80.8)$ & NS \\
\hline Stent, $n(\%)$ & $204(85.71)$ & $485(85.39)$ & NS \\
\hline II B/III A inhibitors, $n(\%)$ & $51(17.0)$ & $118(16.8)$ & NS \\
\hline Final TIMI $3, n(\%)$ & $261(92.9)$ & $626(94.0)$ & NS \\
\hline CABG (immediately), $n(\%)$ & $8(2.85)$ & $26(3.9)$ & NS \\
\hline CABG (urgent), $n(\%)$ & $21(7.5)$ & $54(8.1)$ & NS \\
\hline
\end{tabular}

and prior PCI $(P=0.0364)$ among women than men. Women in the STEMI group were older $(P<0.001)$ and had higher rates of hypertension $(P=0.0012)$ and diabetes $(P<0.001)$ than the STEMI men. STEMI group women were less likely ever to have smoked $(P<0.001)$. Women presenting with NSTEMI had a higher heart rate $(P=0.0053)$, longer duration of infarct pain $(P=0.0225)$, and less frequently underwent immediate bypass surgery $(P=0.0092)$ in comparison to men. No other significant differences in clinical and angiographic data between women and men in both the STEMI and NSTEMI groups were shown. The incidence of endpoints in women was similar to that of men in the NSTEMI group, while women suffering from STEMI died with higher frequency $(P=$ $0.0063)$ than STEMI men. Further analysis showed lower rates of creatine kinase $(P=0.0253)$ and a lower incidence of rhythm disorders $(P=0.0302)$ in NSTEMI women compared to men. In the STEMI group, lower rates of creatine kinase were also observed among women; in this group male patients more often required the use of an intra-aortic balloon pump $(P=0.0316)$ but they were 


\section{Endpoints}

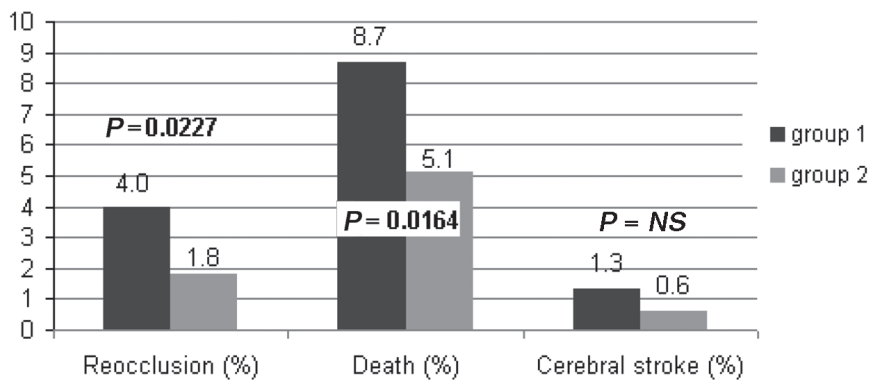

Figure 1. Clinical endpoints.

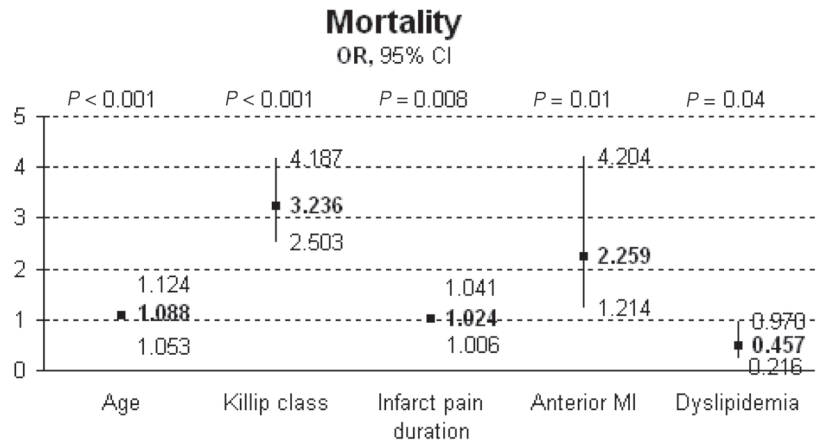

Figure 2. Mortality odds ratio.

diagnosed less frequently with ventricular tachycardia $(P=0.0128)$ than were STEMI women. In the use of drugs, the only difference in the NSTEMI group was that calcium channel inhibitors and sartans were more commonly administered to women $(P=0.049$ and $P=0.0028)$ than to men, while in the STEMI group men were more often prescribed acetylsalicylic acid $(P=0.0186)$ in comparison to women.

In an unadjusted comparison of mortality, death occurred more frequently among women $(P=0.0164)$. All cases of death in both studied groups were of cardiovascular origin. Multivariate logistic-regression techniques were used to determine the independent death related factors in women and men and their significances. We adjusted for age, hypertension, diabetes, dyslipidemia, family history, smoking status, history of myocardial infarction, history of PCI, history of CABG, Killip class, ejection fraction, myocardial infarction anterior location, myocardial infarction postero-infero-lateral location, STEMI, NSTEMI, duration of infarct pain, time of transportation, door-to-needle time, needle-to- 
reperfusion time, and extent of coronary disease. Single sex adjustment did not reveal any significant influence of gender on the risk of death. After adjustment for age, there was an insignificant trend toward an increased risk of death. The adjustment for other data and possible morbid factors listed above indicated that the statistically significant independent co-morbid factors in the 30-day mortality were as follows (regarding strength): Killip class, age, infarct pain duration, and myocardial infarction anterior location (particular data are presented in Figure 2). Furthermore, dyslipidemia tended to lower the risk of death.

\section{Discussion}

Many studies ${ }^{1,6,12)}$ have shown that women suffering from acute coronary syndrome are older, have higher rates of such risk factors as hypertension, dyslipidemia and diabetes, and are less likely to have ever smoked than men. Moreover, women have lower incidences of previous myocardial infarctions and previous coronary interventions $(\mathrm{CABG}, \mathrm{PCI})$. In general, women have signs and symptoms of coronary artery disease ten years later than men as a result of the protective effect of estrogens. Our results corroborate these observations. However, dyslipidemia, previous coronary interventions, and previous myocardial infarction occurred with similar frequencies in both of our groups.

In our study, women were more frequently diagnosed with NSTEMI, which is in accordance with data from a previous paper. ${ }^{6}$ The general condition of female patients at admission was comparable to that of males, and this makes the results more valuable. The analysis of the single NSTEMI group did not reveal any other differences between the genders than the analysis of the general study population did or any other differences that could possibly explain the higher NSTEMI frequency in females. The only distinctions between females and males in the NSTEMI group in comparison to the entire population of 1003 patients in gender analysis were the lower frequency of previous PCI, longer duration of infarct pain, and higher rate of three-vessel disease. On the other hand, the incidence of endpoints between genders in the NSTEMI group was not significantly different. Our study is partially consistent with the results of previous investigators. ${ }^{6,13)}$ There were also no other differences between genders in the STEMI group other than those reported from general cohort gender analysis.

A majority of papers published so far ${ }^{1,6,12)}$ have shown that women undergo coronary interventions in acute coronary syndromes less frequently than men. The complex explanation for this situation is ambiguous and comprises different signs and symptoms of acute coronary syndromes (atypical chest pain in women), preferences for medical treatment expressed by women, or the belief presented by some physicians that coronary angiography in women is of less value 
than in men. ${ }^{14)}$ Some papers have showed that women died more frequently, especially the older ones and those presenting with acute myocardial infarction, compared to men. ${ }^{8,9)}$ Our results are contrary to previously cited papers. Women underwent coronary angioplasty with consecutive revascularization, either percutaneous or surgical, as often as men. The whole medical course from the pain onset until culprit vessel opening did not differ between our 2 groups, however, women stayed in the hospital one day longer. Postdischarge medical treatment was similar in both groups (except calcium channel inhibitors and angiotensin converting enzyme inhibitors). Our results correlate with the results of other studies $^{15,16)}$ and the multicenter randomized trial TACTICS-TIMI 18 which all have proved the efficacy of early invasive treatment in acute coronary syndromes regardless of gender. ${ }^{17)}$

We must emphasize that hemorrhagic complications, despite the higher numbers of all complications in female groups reported so far, ${ }^{7,18)}$ were low in both groups in our study.

In the 30 day long follow-up, we reported higher incidences of death and TLR in women relative to men, findings that were similar to those of the KAMIR Investigators. ${ }^{19)}$ The multivariate analysis partially explains the more frequent mortality among the female population suffering from myocardial infarction. The results confirm age to be the most significant predictor of death, ${ }^{5,6}$ however, only in correlation with Killip class, infarct pain duration, and anterior MI localization. This is relevant to data from gender comparison in the general population, where women were significantly older than men, which many other authors also have reported. ${ }^{1,6,12)}$ No influence of gender on mortality was detected by our multivariate analysis, which correlates with other papers. ${ }^{20,21)}$ Some other studies reported female gender to be a firm risk factor of death ${ }^{22,23)}$ although studies conducted on larger cohorts and involving different populations should be compared carefully. The same multivariate analysis showed that dyslipidemia influences the risk of death by a decrease in its level. This controversial finding may relate to the fact of previous chronic drug treatment for dyslipidemia and its potentially positive effects on the outcome and death risk decrease. However, such an association with the mortality is arguable and is not of great significance (odds ratio, 0.46; 95\% confidence interval, 0.22 to $0.97 ; P=0.04$ ).

It remains uncertain whether the differences in the reocclusion rate reflect clinical differences, more coexistent conditions in women than in men, or a pathophysiologic distinction between men and women. There is also doubt as to whether gender is a risk factor for reocclusion after PCI. Previous studies have generally characterized women with reduced collateral blood flow associated with total coronary occlusion. ${ }^{24)}$ Moreover, among women we observed an insignificant trend towards more extensive coronary artery disease occurrence 
(37.5\% of women versus $29.5 \%$ of men suffered from 3-vessel disease) while single vessel disease was diagnosed more frequently among men than women $(P=0.0402)$, which can result in better outcomes in men. It must be said that the widespread use of stents in our centre began in 2003 and may be partially responsible for such outcomes. The rate of reocclusion observed in the female population can be also explained by the less use of antithrombic agents after percutaneous intervention and stent implantation in this group regarding the greater risk of bleeding. Female gender was associated with moderate or severe bleeding only in the group with ST elevation, however, such a tendency was also reported in a NSTEMI group. ${ }^{6}$ Furthermore, along with the already proven higher age of female population studied here, the protective role of estrogens decreases. Hypoestrogenemia was the most powerful predictor of angiographic coronary artery disease in a multivariate model. ${ }^{25)}$ This may be explained by the smaller coronary artery size. The left main and left anterior descending arteries are smaller in women, independent of body size. This suggests an intrinsic sex effect on coronary dimensions ${ }^{26)}$ and explains the significant and independent influence of anterior myocardial infarction on death in our analysis. This correlates with other reports ${ }^{6,27)}$ and studies proving that female gender is not an independent death risk factor in acute coronary syndrome. ${ }^{28)}$

Conclusion: The medical course of myocardial infarction in women is similar to that in men, as is the treatment of acute coronary syndrome which does not differ significantly between women and men. In our study, patients from both groups underwent invasive examination followed by consecutive interventional treatment (PCI, CABG) with similar frequency. However, this finding is not reflected in the outcomes. Women had higher risks of death and target lesion reocclusion in 30 day follow-up. Taking this into consideration, we should attempt to identify the factors responsible for this situation by expanding the analysis to larger populations to allow firm conclusions to be drawn.

\section{REFERENCES}

1. Vaknin-Assa H, Assali A, Fuchs S, Zafrir N, Kornowski R. Prognostic impact of sex on clinical outcomes following emergent coronary angioplasty in acute myocardial infarction. Coron Artery Dis 2006 Feb; 17(1): 1-5.

2. Fox KA, Poole-Wilson P, Clayton TC, et al. 5-year outcome of an interventional strategy in non-STelevation acute coronary syndrome: the British Heart Foundation RITA 3 randomised trial. Lancet 2005; 366: 914-20.

3. Berger JS, Brown DL. Gender-age interaction in early mortality following primary angioplasty for acute myocardial infarction. Am J Cardiol 2006 Nov 1; 98(9): 1140-3.

4. Hochman JS, McCabe CH, Stone PH, et al. Outcome and profile of women and men presenting with acute coronary syndromes: a report from TIMI IIIB. TIMI Investigators. Thrombolysis in Myocardial Infarction. J Am Coll Cardiol 1997; 30: 141-8.

5. Vaccarino V, Parsons L, Every NR, Barron HV, Krumholz HM. Sex-based differences in early mortal- 
ity after myocardial infarction. N Engl J Med 1999; 341: 217-25.

6. Hochman JS, Tamis JE, Thompson TD, et al. Sex, clinical presentation, and outcome in patients with acute coronary syndromes. Global Use of Strategies to Open Occluded Coronary Arteries in Acute Coronary Syndromes IIb Investigators. N Engl J Med 1999; 341: 226-32.

7. Jacobs AK, Johnston JM, Haviland A, et al. Improved outcomes for women undergoing contemporary percutaneous coronary intervention: a report from the National Heart, Lung and Blood Institute Dynamic Registry. J Am Coll Cardiol 2002; 39: 1608-14.

8. Antoniucci D, Valenti R, Moschi G, et al. Sex-based differences in clinical and angiographic outcomes after primary angioplasty or stenting for acute myocardial infarction. Am J Cardiol 2001; 87: 289-93.

9. Lansky AJ, Hochman JS, Ward PA, et al. Percutaneous coronary intervention and adjunctive pharmacotherapy in women: a statement for healthcare professionals from the American Heart Association. Circulation 2005; 111: 940-53.

10. Milcent C, Dormont B, Durand-Zaleski I, Steg PG. Gender differences in hospital mortality and use of percutaneous coronary intervention in acute myocardial infarction: microsimulation analysis of the 1999 nationwide French hospitals database. Circulation 2007; 115: 833-9.

11. Broda G, Rywik S. Wieloośrodkowe ogólnopolskie badanie stanu zdrowia ludności projekt WOBASZ Zdefiniowanie problemu oraz cele badania. Kardiol Pol 2005; 63: 601-13.

12. Argulian E, Patel AD, Abramson JL, et al. Gender differences in short-term cardiovascular outcomes after percutaneous coronary interventions. Am J Cardiol 2006 1; 98: 48-53.

13. Anand SS, Xie CC, Mehta S, et al. Differences in the management and prognosis of women and men who suffer from acute coronary syndromes. J Am Coll Cardiol 2005; 46: 1845-51.

14. Rathore SS, Wang Y, Radford MJ, Ordin DL, Krumholz HM. Sex differences in cardiac catheterization after acute myocardial infarction: the role of procedure appropriateness. Ann Intern Med 2002; 137: 487-93.

15. Rathore SS, Chen J, Wang Y, Radford MJ, Vaccarino V, Krumholz HM. Sex differences in cardiac catheterization: the role of physician gender. JAMA 2001; 286: 2849-56.

16. Moriel M, Behar S, Tzivoni D, Hod H, Boyko V, Gottlieb S. Management and outcomes of elderly women and men with acute coronary syndromes in 2000 and 2002. Arch Intern Med 2005; 165: 1521-6.

17. Cannon CP, Weintraub WS, Demopoulos LA, et al. Comparison of early invasive and conservative strategies in patients with unstable coronary syndromes treated with glycoprotein IIb/IIIa inhibitor tirofiban. N Engl J Med 2001; 344: 1879-87.

18. Poludasu S, Cavusoglu E, Clark LT, Marmur JD. Impact of gender on in-hospital percutaneous coronary interventional outcomes in African-Americans. J Invasive Cardiol 2007; 19: 123-8.

19. Korea Acute Myocardial Infarction Registry (KAMIR) Investigators, Lee KH, Jeong MH, et al. Gender differences of success rate of percutaneous coronary intervention and short term cardiac events in Korea Acute Myocardial Infarction Registry. Int J Cardiol 2008; 130: 227-34.

20. Hasdai D, Porter A, Rosengren A, Behar S, Boyko V, Battler A. Effect of gender on outcomes of acute coronary syndromes. Am J Cardiol 2003; 91: 1466-9, A6.

21. Cheng CI, Yeh KH, Chang HW, et al. Comparison of baseline characteristics, clinical features, angiographic results and early outcomes in men vs women with acute myocardial infarction undergoing primary coronary intervention. Chest 2004; 126: 47-53.

22. Theres H, Maier B, Matteucci Gothe R, et al. Influence of gender on treatment and short-term mortality of patients with acute myocardial infarction in Berlin. Z Kardiol 2004; 93: 954-63.

23. Kudenchuk PJ, Maynard C, Martin JS, Wirkus M, Weaver WD. Comparison of presentation, treatment, and outcome of acute myocardial infarction in men versus women (the Myocardial Infarction Triage and Intervention Registry). Am J Cardiol 1996; 78: 9-14.

24. Johansson S, Bergstrand R, Schlossman D, Selin K, Vedin A, Wilhelmsson C. Sex differences in cardioangiographic findings after myocardial infarction. Eur Heart J 1984; 5: 374-81.

25. Bairey Merz CN, Johnson BD, Sharaf BL, et al. Hypoestrogenemia of hypothalamic origin and coronary artery disease in premenopausal women: a report from the NHLBI-sponsored WISE study. J Am Coll Cardiol 2003; 41: 413-9. 
26. Sheifer SE, Canos MR, Weinfurt KP, et al. Sex differences in coronary artery size assessed by intravascular ultrasound. Am Heart J 2000; 139: 649-53.

27. Kostis JB, Wilson AC, O'Dowd K, et al. Sex differences in the management and long-term outcome of acute myocardial infarction. A statewide study. MIDAS Study Group. Myocardial Infarction Data Acquisition System. Circulation 1994; 90: 1715-30.

28. Mehilli J, Kastrati A, Dirschinger J, Bollwein H, Neumann FJ, Schömig A. Differences in prognostic factors and outcomes between women and men undergoing coronary artery stenting. JAMA 2000; 284: 1799-805. 